DEMOGRAPHIC RESEARCH

VOLUME 43, ARTICLE 9, PAGES 217-244

PUBLISHED 24 JULY 2020

http://www.demographic-research.org/Volumes/Vol43/9/

DOI: 10.4054/DemRes.2020.43.9

Research Article

\title{
The lasting impact of parental migration on children's education and health outcomes: The case of China
}

\section{Zai Liang \\ Feinuo Sun}

This publication is part of the Special Collection on Life-Course Decisions of Families in China, organized by Guest Editors Bing Xu, William A.V. Clark, Eric Fong, and Li Gan.

\section{(C) 2020 Zai Liang \& Feinuo Sun.}

This open-access work is published under the terms of the Creative Commons Attribution 3.0 Germany (CC BY 3.0 DE), which permits use, reproduction, and distribution in any medium, provided the original author(s) and source are given credit.

See https://creativecommons.org/licenses/by/3.0/de/legalcode. 


\section{Contents}

$\begin{array}{lll}1 & \text { Introduction } & 218\end{array}$

2 Life-course cumulative inequality, from childhood to adulthood 219

3 From the short-term impact to the long-term impact of parental 221 migration on children

$4 \quad$ Data and methods $\quad 223$

$\begin{array}{lll}5 & \text { Findings } & 227\end{array}$

6 Summary and discussion $\quad 232$

$7 \quad$ Acknowledgments 235

References $\quad 236$

$\begin{array}{ll}\text { Appendix } & 240\end{array}$ 


\title{
The lasting impact of parental migration on children's education and health outcomes: The case of China
}

\author{
Zai Liang ${ }^{1}$ \\ Feinuo Sun $^{2}$
}

\begin{abstract}

\section{BACKGROUND}

Recent years have witnessed a surge in studies that examine the education and health consequences of parental migration on children. Most studies focus on the short-term consequences and there is an urgent need to study the long-term consequences.
\end{abstract}

\section{OBJECTIVE}

Capitalizing on a unique survey in China, we aim to study the lasting educational and health consequences of parental migration on children.

\section{METHODS}

We measure respondents' experiences of being left behind during different stages of life, namely prior to elementary school, during elementary school, and during middle school. Among people who have experienced being left behind, we further classify the experience into several categories such as left behind with grandparents and left behind with others. We estimate a variety of regression models taking into account respondents' different living arrangements when growing up.

\section{RESULTS}

We find that being left behind with grandparents during the elementary school stage compromises educational attainment. Individuals who were left behind with others during primary school were more likely to have poor self-rated and mental health at the time of the survey. The long-term educational and health consequences of parental migration raise new concerns for today's left-behind children.

\section{CONCLUSIONS}

We show that parental migration, especially during elementary school years, is likely to have long term consequences for children's educational and health outcomes.

\footnotetext{
${ }^{1}$ Department of Sociology, State University of New York, USA, and Department of Sociology, Xi'an Jiaotong University, China. Email: zliang@albany.edu.

${ }^{2}$ Department of Sociology, State University of New York, USA.
} 


\section{CONTRIBUTION}

We show that parental migration has long-term consequences for children's educational and health outcomes.

\section{Introduction}

In a recent paper published in the American Sociological Review, Ferraro, Schafer, and Wilkinson (2016) point to the rising number of studies using the life course approach to study a variety of research topics, such as education (Conley and Bennett 2000), socioeconomic achievement (Elman and O'Rand 2004; Hogan 1981), and health and mortality (Case, Fertig, and Paxson 2005; Hayward and Gorman 2004; Kuh and BenShlomo 1997). This increased attention to the life course approach goes beyond the field of sociology. Though not framed in the language of life course analysis, Nobel prize-winning economist James Heckman's (2006) work points to the importance of investing in early childhood for educational and occupational attainment, especially for children from disadvantaged families.

This focus on how earlier life disadvantages or advantages affect subsequent life course events (such as going to college, marriage, and jobs) is a major departure from the approaches widely used in earlier studies, which pay limited attention to the impact of early childhood events on subsequent individual outcomes. Children being in a stressful situation can cause emotional problems and disruption in school, but it is more important to know whether this early life event has long-lasting consequences. The policy implications of this approach are clear: If there is enough evidence to see the long-lasting impact of certain events, we can design policies to mitigate the negative impact.

In this paper we examine the possible long-term educational and health consequences of children's early experience of being left behind by migrant parents using unique data collected from adult workers. Some of the workers in this survey experienced parental migration at different stages of their early childhood. Although earlier studies have shed important light on the educational and health consequences of parental migration, all the variables of interest (testing scores, health measures, behavioral problems) are measured around a similar time in the children's childhood. The literature on child development shows that sometimes children can overcome certain negative outcomes (such as poor grades or poor health) and recover (Mayer 2009): children can turn out to be equally successful in their subsequent educational attainment, career, and personal health. Therefore, it is important to ask if the negative outcomes observed among children who are left behind last into adulthood. Clearly, the 
policy prescriptions will be very different if the educational and health consequences of parental migration tend to last far beyond childhood.

Our paper explores the long-term consequences of parental migration. We first provide a brief review of the literature and discuss the approach and framework used. We examine the educational attainment, self-rated health, and mental health of the adult workers who participated in the survey and measure parental migration before primary school, during primary school, and in middle school. We then estimate regression models of education, self-rated health, and mental health at the time of survey (when all the children were adults), revealing some major negative education and health consequences. We discuss policy implications at the end of the paper.

\section{Life-course cumulative inequality, from childhood to adulthood}

Perhaps more than anyone else, sociologist Glenn Elder is associated with the idea and widespread application of the life course perspective in social science research (Elder 1998; Mayer 2009). According to Elder (1998: 2), "the multiple trajectories of individuals and their developmental implications are basic elements of the 'life course', ...". Mayer (2009) outlines four key elements of the life course perspective. First, prior life course events have strong impacts on subsequent life course outcomes. Second, changes in human lives are studied across cohorts. Third, changes in human lives are studied across domains (such as work and family). Finally, life course development is analyzed as the outcome of personal traits as well as of cultural frames and structural conditions such as large-scale transformations of society.

In an example of this life course approach, Elder (1974) studied a small group of people who experienced the Great Depression in the United States. Using 30 years of life history, Elder (1974) carefully analyzed the major life events and transitions of these people such as socialization, transition to adulthood, educational attainment, and wages. Interestingly, the Great Depression had a different impact on people from different social backgrounds. Adolescents from more deprived households became more autonomous and shifted away from home and parents than adolescents from middle-class households. Somewhat surprisingly, this variation in the impact of the Great Depression manifested in other aspects as well. For example, children from middle-class families adapted better psychologically than children from lower-class families, though the exact reasons for this difference are not clear. Elder's early study reveals that large-scale societal transformations may have either positive or negative consequences for people later in life.

Following this life course tradition, Zhou and Hou (1999) systematically examine how China's Cultural Revolution (1966-1976) affected the life chances of individuals 
who experienced this major social transformation. In particular, they examine the impact of the experience of being 'sent-down', referring to the migration of urban youth to the countryside during the Cultural Revolution. They study (1) who was sent down to the countryside and (2) the long-term consequences of being sent down on education (college attainment) and wages. They reveal some quite surprising findings. Female employees who were sent down had higher income than female employees with no such experience. All social groups had an equal chance of being sent down. In addition, those who were sent down were more likely to complete college education. Zhou and Hou (1999) argue that the rural experience may have fostered a unique life perspective in the sent-down young, bolstering their perseverance and risk-taking attitudes as they faced new opportunities.

In recent years, research in this area has moved in new directions. Several sociologists have formulated different perspectives on cumulative advantage/disadvantage. Blau and Duncan (1967) conceived the idea of cumulative disadvantage in their classic work on social stratification, suggesting that group differences at different stages of individual lives tend to have long-term implications. The case of African Americans and whites is used to illustrate their argument. DiPrete and Eirich (2006) suggest that Blau and Duncan's approach can be used to understand how exposure to situations such as growing up in a single-parent vs. a two-parent household can have long-lasting socioeconomic consequences. Parental migration resulting in a changed family structure fits this line of inquiry. In a different context, Merton (1968) observed that people who are already established in the sciences tend to be rewarded a lot more than those who are not so established, a phenomenon he termed the 'Matthew effect.' Although Merton's context is a positive reward system of 'winner takes all,' the logic is certainly applicable to other negative contexts (cumulative disadvantage). People who face early life disadvantages "can face a cascade of additional risks to health, wealth, and well-being" (Ferraro and Kelley-Moore 2003: 709). The key insight from the cumulative disadvantage theory is "how early advantage and disadvantage is critical to how cohorts become differentiated over time" (Ferraro and Kelley-Moore 2003: 708).

Several important studies in the western literature have confirmed this long-term impact of early childhood disadvantage. Case, Fertig, and Paxson (2005) show that cohort members born into poor families experience poor childhood health and are associated with lower earnings in middle age. Likewise, Hayward and Gorman (2004) demonstrate that men's mortality is associated with childhood socioeconomic conditions and family living arrangement. Hayward and Gorman's family living arrangement is similar to the situation in our study where children lived with one parent or with relatives when their biological parent(s) migrated. Ferraro and Kelley-Moore 
(2003) show that obesity in early life is related to lower body disability during adult and old ages.

Perhaps the most important advance in this line of research was when scholars began to identify possible mechanisms linking early childhood disadvantage to outcomes in later life. Ferraro, Schafer, and Wilkinson (2016) outline several possibilities in the case of health outcomes. First, childhood disadvantage may reduce the likelihood of socioeconomic status (SES) attainment, which affects adult health. Second, early disadvantage leads to behavioral responses and lifestyle choices in adolescence and young adulthood that compromise health outcomes. These variables include smoking, drinking, and obesity. Third, ample evidence suggests that precarious families lead to vulnerabilities in offspring's social functioning. These factors mediate childhood disadvantage and adult health outcomes. Ferraro, Schafer, and Wilkinson (2016) show strong evidence that childhood disadvantage is linked to health problems in middle and later life.

\section{From the short-term impact to the long-term impact of parental migration on children}

There have been many studies on the impact of parental migration on children's health and education, the topic of this paper. Most previous studies on rural China use crosssectional data or longitudinal data (during childhood years), which often reveal that children from migrant families tend to exhibit poorer academic performance than children from non-migrant families (Liang 2016; Zhang et al. 2014; Zhou, Murphy, and Tao 2014). Other studies using cross-sectional data show no impact of parental migration on children's education and health (Ren and Treiman 2015; Xu and Xie 2015). If a child does not do well in primary school, chances are the child is less likely to enter a high-quality secondary school, which then reduces the chances of the child going to college. The same logic can be used to argue for long-term health consequences. Given the fact that many earlier studies conclude that parental migration is associated with poor mental health consequences, we argue that it is possible that the impact on education and health can last well into adulthood.

The life course perspective provides an important theoretical framework for our paper. First, we argue that parental migration in children's early lives is linked to key socioeconomic outcomes in later life. The cumulative disadvantage suggests possible mechanisms such as parental migration lead to poor educational outcomes in primary school, which then lead to poor educational outcomes at subsequent stages (middle school, high school, and final educational achievement during adulthood). Second, the life course perspective studies human lives across domains. In our case, we study how 
an early life course event (being left behind by parent/s) affects children's lives in two key domains, education and health. Finally, China's great migration - over 200 million people migrating from the countryside to work in the cities - is a large-scale societal transformation that provided enormous opportunities and socioeconomic mobility for millions of Chinese people, but which also has possible negative consequences for certain segments of Chinese society (in our case, left-behind children) (Yue, Liang, and Wang 2020).

Some research finds that parental migration is highly correlated with children's educational and health outcomes, and the impacts can last for many years, while the type and timing of the left-behind experience also plays a role (Liang 2016; Lu 2012). One challenge to evaluating the impact of parental migration on children left behind is that forces exist that operate in opposite directions. On the one hand, because migration is a strategy to improve socioeconomic circumstances it can be beneficial for the educational and health outcomes of children in migrating households (Stark and Bloom 1985; Edwards and Ureta 2003; Hildebrandt and McKenzie 2005; Liang, Li, and Ma 2013). From this perspective the remittances received as a result of parental migration can benefit the education and health of the children left behind .On the other hand, family separation and the absence of parental supervision are found to be detrimental to left-behind children in terms of school engagement and success (Robles and Oropesa 2011), health (De Brauw and Mu 2011; Wen and Lin 2012), and mental health issues such as distress and anxiety (Shi et al. 2016). Because of these competing forces the different types and timings of left-behind experience can lead to varying outcomes.

When parents (especially both parents) leave home the children are always cared for and supervised by their grandparents and other relatives (Lu 2012; Ye and Murray 2005; De Brauw and Mu 2011). The extended kinship system can provide supplementary physical and psychological benefits that can alleviate, if not eliminate, the negative impact of separation from parents and prevent left-behind children from further distress (Lu 2012; Falbo 1991). In rural China it is also a common practice for elder siblings to take care of younger children ( $\mathrm{Lu}$ 2012; Ye and Murray 2005). According to studies on the effects of family arrangements on youth behaviors (Case and Katz 1991; Hayward and Gorman 2004), different family backgrounds can lead to different outcomes for left-behind children. As for the timing of the left-behind experience, children of different ages are influenced differently. $\mathrm{Lu}$ (2012) finds that the absence of parents has a significant impact on younger children since they are more vulnerable, but revenues from migration benefit left-behind children in middle school due to increasing educational expenses, which is consistent with previous studies (Ermisch and Francesconi 2001). Transitions in family status and the left-behind experience can also affect children's well-being, and a stable family structure results in better outcomes for children (Lu 2012; Raley and Wildsmith 2004). Therefore, it is 
necessary to consider the type and timing of being 'left-behind,' as well as the change in left-behind status.

We argue that the long-term outcome of the disadvantages of left-behind status may be mediated by how the left-behind status is arranged. As we see in Elder's study, children from different social classes fared differently in the Great Depression. In the case of China, we argue that the impact of parental migration on children's outcomes later in life is also affected by the actual childcare arrangement, - who took care of the left-behind children when the parent(s) migrated. Children could be taken care of by grandparents (the most common arrangement), a non-migrant parent, or other relatives. Some children were also placed in boarding schools.

\section{Data and methods}

The setting of this research is the Pearl River Delta (PRD) and the Yangtze River Delta (YRD), which are the most developed areas and the main destination areas of interprovincial population migrants in China (see Figure 1 for the locations of PRD and YRD). The total proportion of the floating populations in these two regions is $35.4 \%$. These two regions account for more than $50 \%$ of China's interprovincial floating population (Liang, Li, and Ma 2014). Thus, the study of floating migrants in these regions is likely to be relevant to the rest of the country as well.

The data used in this study is from a large survey of migrant workers in the PRD and YRD areas that was conducted in July and August of 2010. The project focused on migrant workers who were involved in cross-county or cross-district migration. The sample allocation of this survey is based on the proportion of urban migrant population in these two regions, controlling for distributions of gender, occupation, and region. The study collected 4,151 valid questionnaires, 2,046 for the PRD area and 2,106 for the YRD area (Liu, Yong, and Shu 2011). This paper focuses on 2,385 respondents who were born after 1980 and who provided information about left-behind experience when they were growing up.

The most important feature of the survey from our point of view is that it allows us to study the long-term effects of the left-behind experience, as it provides retrospective information about who the respondents were living with when growing up (both parents, single parent, or relatives). This retrospective history information, we believe, is sufficiently accurate, because people were only asked to recall who they lived with in their early lives. Unfortunately, we do not have information on the duration of the leftbehind experience. 


\section{Figure 1: The location of PRD and YRD in China}

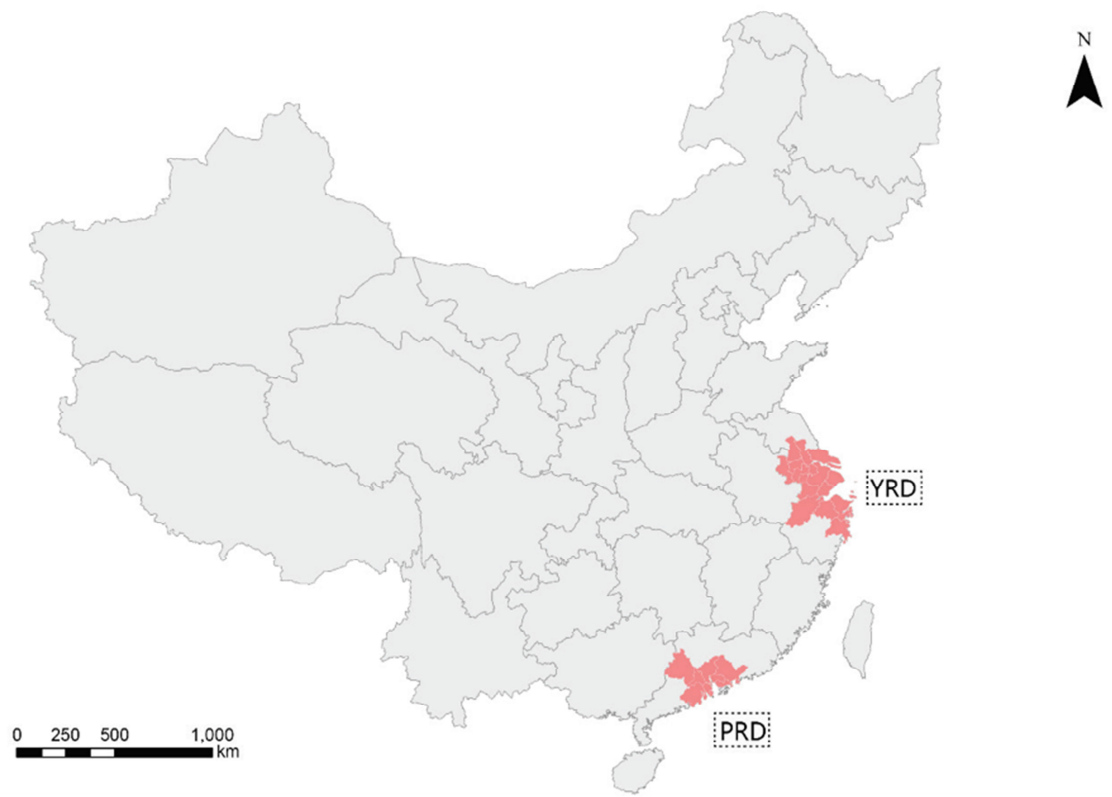

Source: Figure 1 based on Fig.1 in Journal of the Geographical Society of Berlin 148(1) by Zhao, Derruder, and Huang (2017).

Our goal is to examine the long-term impact of parental migration on education and health using left-behind experience (when the respondents were children) as a key independent variable. The dependent variables we use are education, health, and mental health. Given the generally lower education level of migrant workers, we used 'technical high school' as the cutoff point of the dichotomy variable: "graduated from technical secondary school or above." In other words, completion of technical high school or above is considered to be quite an achievement for this group of respondents. The second dependent variable for our study is self-rated health, another widely used measure of health conditions at the time of survey. There are five categories of response: very good, good, fair, poor, and very poor.

The third dependent variable is the mental health of migrant workers measured by the General Health Questionnaire (GHQ), which includes 12 questions (see Appendix 1). The GHQ was first introduced by Goldberg in 1978 and has been translated into many different languages. It consists of 6 positive statements and 6 negative statements that refer to symptoms of psychological distress that the respondents may have 
experienced during the previous two weeks (Von Korff and Üstün 1995). The GHQ method, with satisfactory psychometric properties, has been used in some earlier studies in the Chinese literature (Zhang et al. 2008; Liu, Zheng, and Sun 2011). It should be noted that the four responses "not at all," "same as usual," "more than usual," and "much more than usual" are coded 0,0,1,1 to help eliminate biases of "middle and end users" and "conceptual distance" between positions (Piccinelli et al. 1993; Goldberg and Williams 1988; Zulkefly and Baharudin 2010). The sum of the scores is calculated as a continuous variable that ranges between 0 and 12, with larger values referring to worse mental health outcomes. Appendix 1 shows the actual wording of the GHQ. The statements in the GHQ range include "loss of sleep due to anxiety" and "feeling unhappy and depressed."

The key independent variables for our study are the experiences of children left behind during any of the following three stages: before primary school, during primary school, or during middle school. During each of these three stages we use dummy variables to measure children's left-behind status: "have not been left behind (living with parents)," "left behind with grandparents," and "left behind with others (including living alone)." For the middle school stage we also include a separate group of "boarding at school."

Based on previous studies in the literature, we include other important variables: age, gender, education years, number of friends, migration duration, hukou (household registration) status (whether holds rural hukou), marriage status (no spouse (single or divorced), spouse in the same city, spouse in another city), as well as region (east, central, west) and the type of location (central city, suburb, towns and villages, countryside).

Our major independent variable of interest, namely early left-behind experience, takes many forms. For example, we have information on the left-behind experience of respondents at three stages of their lives: pre-elementary school, during elementary school, and during middle school. In each of the three stages there is a possibility of being left behind with grandparents or with other relatives (including brothers, sisters, and other non-immediate family). For left-behind experience during middle school there is also the category of boarding school.

Given the nature of our three dependent variables, we used logistic models for educational attainment, an ordered logit model for self-rated health, and the OLS model for mental health GHQ score. To account for the potential selection bias of being left behind, we employed the inverse probability treatment weighting (IPTW) approach with propensity score using generalized boosted models (GBM) for multiple treatments, since our key independent variables are categorical. The GBM approach uses an iterative process with multiple regression trees to achieve the best balance between treated and control group and is found to be superior to multinomial logistic regression 
(McCaffrey et al. 2013). The pairwise average treatment effects (ATE) of not being left behind, being left behind with grandparents, being left behind with others, and boarding at school for each respondent are estimated based on pretreatment covariates including age, gender, region, and contextual factors of origin city (percentage of non-agricultural population, GDP per capita, and employment rate). The statistics of county-level factors were drawn from the statistical yearbook for 1996, a year that most migrant workers in our sample were in primary school, to estimate the social conditions of their parents' migration. The propensity score is computed as follows:

$$
P_{t}(\boldsymbol{X})=\operatorname{pr}(T[t]=1 \mid \boldsymbol{X})
$$

$P_{t}(\boldsymbol{X})$ indicates the propensity score that an individual with pretreatment characteristics $X$ receives treatment $t$, and $T[t]$ indicates a specific treatment $(t=0,1,2,3)$. The ATE weight is the reciprocal of the propensity for the treatment the respondent received.

$$
w_{i}[t]=\frac{1}{P_{t}\left(\boldsymbol{X}_{\boldsymbol{i}}\right)}
$$

Applying the weights makes different treatment groups balanced with each other on the pretreatment covariates we considered, thus yielding robust estimates of the causal effects of left-behind status on education, self-rated health, and mental health outcomes. Multinomial logistic regression results for treatment (left-behind status) in each of our outcome models are presented in Appendix 2, showing how the pretreatment covariates predict the probability of receiving the treatment.

For example, Table A-2 (in the Appendix) shows that during elementary school, younger children are more likely to be left behind with their grandparents rather than living with their parents, while living in cities with a higher employment rate reduces the likelihood of being left behind with others, net of the effects of all other control variables. Thus, the probabilities of being left behind during elementary school are significantly different for children of different ages and for children in different cities. By applying propensity score weighting we are able to make the three groups of children - left behind with grandparents, left behind with others, not left behind comparable with each other on those pre-treatment covariates, minimizing possible confounding effects on our outcomes of interest. Tables A-3 to A-5 can be interpreted similarly. 


\section{Findings}

Table 1 shows some basic descriptive statistics. We see that the migrant workers in our sample are relatively young with a mean age of 24 years. The mean level of education is 10 years, so most of them did not finish high school. This provides further justification for our decision to treat technical high school as a major achievement for this group of respondents. Most of them (nearly 88\%) were not left behind before or during primary school. Figure 2 shows the duration between year of being left behind and 2010, the time of the survey. Essentially, we want to gauge the number of years passed since the respondents experienced being left-behind in childhood. For migrant workers who were left behind prior to primary school it often happened about 18 years ago. For those who were left-behind during primary school it was often about 13 years ago. This time period between the left-behind experience and our current measuring of education and health outcomes is ideal for us to detect any long-term impact.

\section{Table 1: Descriptive statistics}

\begin{tabular}{|c|c|c|}
\hline Variable & Mean (S.D.) & $\mathbf{N}$ \\
\hline Has graduated from technical high school or above (\%) & 34.38 & 2,385 \\
\hline \multicolumn{3}{|l|}{ Self-rated health } \\
\hline Very good (\%) & 23.64 & 2,382 \\
\hline Good (\%) & 40.80 & 2,382 \\
\hline Fair $(\%)$ & 30.86 & 2,382 \\
\hline Poor $(\%)$ & 4.15 & 2,382 \\
\hline Very poor $(\%)$ & 0.55 & 2,382 \\
\hline GHQ score & $1.64(2.11)$ & 2,333 \\
\hline Age & $23.52(3.53)$ & 2,385 \\
\hline Education years & $10.16(2.87)$ & 2,385 \\
\hline Number of friends & $6.06(6.47)$ & 2,367 \\
\hline Migration duration (in years) & $4.70(3.57)$ & 2,362 \\
\hline Female (\%) & 50.65 & 2,385 \\
\hline \multicolumn{3}{|l|}{ Region } \\
\hline East (\%) & 34.56 & 2,384 \\
\hline Central (\%) & 39.48 & 2,384 \\
\hline West (\%) & 25.96 & 2,384 \\
\hline Has studied in schools in destination cities & 2.66 & 2,369 \\
\hline Has rural hukou & 83.40 & 2,385 \\
\hline \multicolumn{3}{|l|}{ Marital status } \\
\hline No spouse (single or divorced) (\%) & 68.43 & 2,385 \\
\hline Spouse is in the same city (\%) & 26.41 & 2,385 \\
\hline Spouse is in another city (\%) & 5.16 & 2,385 \\
\hline
\end{tabular}




\section{Table 1: (Continued)}

\begin{tabular}{lcc}
\hline Variable & Mean (S.D.) & N \\
\hline Hometown status & 4.28 & 2,385 \\
Central city (\%) & 4.78 & 2,385 \\
Suburb (\%) & 22.81 & 2,385 \\
Town or county (\%) & 68.13 & 2,385 \\
Rural village (\%) & 88.74 & 2,372 \\
Before elementary school: & 10.71 & 2,372 \\
Has not been left behind (\%) & 0.55 & 2,372 \\
Has been left behind with grandparents (\%) & & 2,347 \\
Has been left behind with others (\%) & 87.52 & 2,347 \\
During elementary school: & 10.82 & 2,347 \\
Has not been left behind (\%) & 1.66 & 2,266 \\
Has been left behind with grandparents (\%) & & 2,266 \\
Has been left behind with others (\%) & 70.39 & 2,266 \\
During middle school: & 8.07 & 2,266 \\
Has not been left behind (\%) & 5.08 & 16.46 \\
Has been left behind with grandparents (\%) & & \\
Has been left behind with others (\%) & & \\
Has been boarded at school (\%) & & \\
\hline
\end{tabular}

Figure 2: Average years since the respondents were left behind

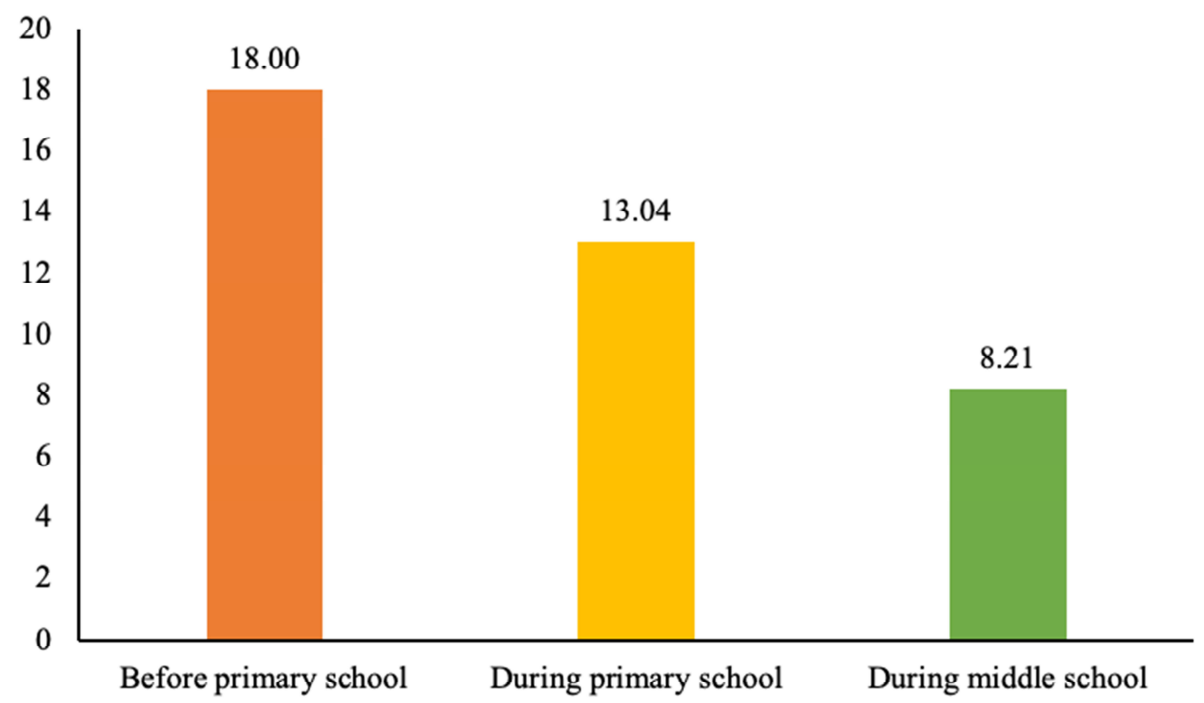


In Table 2 we present results of the model of educational attainment (achieving technical high school education). With a p-value smaller than 0.001 , we see that individuals with rural hukou were less likely to attend technical high school, reflecting a long-standing educational disparity between rural and urban China. In addition, migrants from western China are less likely to obtain a technical high school education than migrants from eastern China.

Table 2: Logistic regression for graduation from technical high school or above

\begin{tabular}{|c|c|c|c|c|c|c|c|c|}
\hline \multirow{3}{*}{$\begin{array}{l}\text { Variable } \\
\text { Age }\end{array}$} & \multicolumn{4}{|l|}{ Model 1} & \multicolumn{4}{|l|}{ Model 2} \\
\hline & \multirow{2}{*}{$\begin{array}{l}\text { Coef. } \\
-0.033\end{array}$} & \multirow{2}{*}{$\begin{array}{r}\text { P value } \\
0.340\end{array}$} & \multicolumn{2}{|c|}{$95 \%$ Conf. Interval } & \multirow{2}{*}{$\begin{array}{l}\text { Coef. } \\
0.007\end{array}$} & \multirow{2}{*}{$\begin{array}{r}\text { P value } \\
0.772\end{array}$} & \multicolumn{2}{|c|}{ 95\% Conf. Interval } \\
\hline & & & {$[-0.100$} & $0.035]$ & & & {$[-0.040$} & $0.053]$ \\
\hline Female & -0.357 & 0.129 & {$[-0.818$} & $0.104]$ & -0.201 & 0.206 & {$[-0.512$} & $0.110]$ \\
\hline Has rural hukou & -1.337 & 0.000 & {$[-2.022$} & $-0.652]$ & -1.284 & 0.000 & {$[-1.746$} & $-0.821]$ \\
\hline Has studied in schools in destination cities & -1.302 & 0.106 & {$[-2.880$} & $0.276]$ & -0.184 & 0.618 & {$[-0.909$} & $0.540]$ \\
\hline \multicolumn{9}{|l|}{ East (reference) } \\
\hline Central & -0.316 & 0.248 & {$[-0.851$} & $0.219]$ & -0.308 & 0.084 & {$[-0.657$} & 0.041] \\
\hline West & -0.831 & 0.014 & {$[-1.492$} & $-0.169]$ & -0.792 & 0.000 & {$[-1.199$} & $-0.384]$ \\
\hline \multicolumn{9}{|l|}{ Central city (reference) } \\
\hline Suburb & 0.313 & 0.730 & {$[-1.467$} & 2.093] & -0.875 & 0.105 & {$[-1.932$} & $0.182]$ \\
\hline Town or county & 0.048 & 0.936 & {$[-1.131$} & $1.228]$ & -0.347 & 0.468 & {$[-1.284$} & $0.590]$ \\
\hline Rural village & 0.067 & 0.914 & {$[-1.151$} & $1.285]$ & -0.398 & 0.388 & {$[-1.301$} & $0.506]$ \\
\hline \multicolumn{9}{|l|}{ Has not (never) been left behind (reference) } \\
\hline \multicolumn{9}{|l|}{ Has been left behind: } \\
\hline with grandparents during elementary school & -0.427 & 0.014 & {$[-0.769$} & $-0.085]$ & & & & \\
\hline with others during elementary school & -0.266 & 0.502 & {$[-1.045$} & $0.512]$ & & & & \\
\hline with grandparents during middle school & & & & & -0.095 & 0.655 & {$[-0.510$} & $0.321]$ \\
\hline with others during middle school & & & & & -0.172 & 0.526 & {$[-0.704$} & $0.360]$ \\
\hline boarding at middle school & & & & & 0.494 & 0.000 & {$[0.237$} & 0.751] \\
\hline Constant & 1.714 & 0.096 & {$[-0.303$} & $3.730]$ & 1.043 & 0.172 & {$[-0.455$} & 2.542] \\
\hline Pseudo $\mathrm{R}^{2}$ & 0.067 & & & & 0.075 & & & \\
\hline N & 2,307 & & & & 2,229 & & & \\
\hline
\end{tabular}

Our main goal is to evaluate how early left-behind experience is related to education and health outcomes during adulthood. The task is complicated, as we have information on left-behind experience at three stages (pre-elementary school, during elementary school, and during middle school). For each of these three stages, 
individuals are further classified as left behind with grandparents or left behind with others. For left behind at the middle school stage we have a third category of boarding school. As the models with different combinations of stage and type of left behind are many, we only report the significant findings.

Based on the results in Table 2, given the p-value of 0.014 (between 0.01 and 0.05), we find that being left behind with grandparents during elementary school years is likely to reduce educational attainment (obtaining technical high school education or above). To be more precise, being left behind with grandparents during elementary school years leads to a .427 reduction in the log odds of having a technical high school education. If we use odds ratios, this means the odds of people who were left behind with grandparents during elementary school getting a technical high school education are $65 \%(\exp (-0.427)=0.652)$ of the odds for individuals without left-behind experience.

Interestingly, with a p-value of 0.000 , results from Model 2 in Table 2 reveal that children who went to boarding school during the middle school stage tend to have a more favorable educational outcome when they become adults. Two recent studies show a positive impact of boarding school on educational outcomes. Ma et al. (2013) find that elementary school students who attend boarding school have better grades but worse psychological health than those who live with their family. Liu (2010) also highlights that rural middle boarding school could benefit students' perceived academic self-efficacy. Typically, a teacher is assigned to work with students when classes are over, students are supervised to make sure homework is done, and the schedule is predictable and is followed.

In Table 3 we examine how early left-behind experience is related to self-rated health during adulthood. With a p-value of 0.009 , we find that children who were left behind with others during elementary school have poor health outcomes compared to those who have never been left behind by their parents (see Model 4). Finally, in Table 4 we study the mental health consequences of being left behind when growing up. With a p-value of 0.016 the results show that children who were left behind with others have poorer mental health outcomes than the never left-behind. To be more precise, individuals left behind with others during elementary school years have higher mental health scores by 1.14 units than respondents who were not left behind. 
Table 3: Ordered logistic regression for self-rated health

\begin{tabular}{|c|c|c|c|c|c|c|c|c|}
\hline \multirow{3}{*}{$\begin{array}{l}\text { Variable } \\
\text { Age }\end{array}$} & \multicolumn{4}{|l|}{ Model 3} & \multicolumn{4}{|l|}{ Model 4} \\
\hline & \multirow{2}{*}{$\begin{array}{l}\text { Coef. } \\
0.056\end{array}$} & \multirow{2}{*}{$\begin{array}{r}\text { P value } \\
0.527\end{array}$} & \multicolumn{2}{|c|}{$95 \%$ Conf. Interval } & \multirow{2}{*}{$\begin{array}{l}\text { Coef. } \\
0.042\end{array}$} & \multirow{2}{*}{$\begin{array}{r}\text { P value } \\
0.617\end{array}$} & \multicolumn{2}{|c|}{$95 \%$ Conf. Interval } \\
\hline & & & {$[-0.117$} & $0.228]$ & & & {$[-0.124$} & $0.208]$ \\
\hline Female & -0.499 & 0.017 & {$[-0.910$} & $-0.089]$ & -0.590 & 0.003 & {$[-0.985$} & $-0.195]$ \\
\hline Education years & 0.018 & 0.752 & {$[-0.095$} & $0.131]$ & 0.028 & 0.624 & {$[-0.083$} & $0.138]$ \\
\hline Migration duration (in years) & -0.077 & 0.330 & {$[-0.231$} & $0.078]$ & -0.064 & 0.412 & {$[-0.218$} & 0.089] \\
\hline Number of friends & 0.027 & 0.023 & {$[0.004$} & $0.050]$ & 0.029 & 0.013 & {$[0.006$} & 0.051] \\
\hline \multicolumn{9}{|l|}{ Spouse is in the same city (reference) } \\
\hline No spouse (single or divorced) & -0.383 & 0.109 & {$[-0.851$} & $0.085]$ & -0.380 & 0.136 & {$[-0.880$} & 0.120] \\
\hline Spouse is in another city & -0.308 & 0.538 & {$[-1.290$} & $0.673]$ & -0.406 & 0.338 & {$[-1.237$} & $0.425]$ \\
\hline \multicolumn{9}{|l|}{ East (reference) } \\
\hline Central & 0.273 & 0.270 & {$[-0.212$} & $0.758]$ & 0.260 & 0.291 & {$[-0.222$} & 0.742] \\
\hline West & -0.046 & 0.854 & {$[-0.534$} & $0.443]$ & -0.064 & 0.783 & {$[-0.524$} & 0.395] \\
\hline \multicolumn{9}{|l|}{ Central city (reference) } \\
\hline Suburb & -1.221 & 0.235 & {$[-3.236$} & $0.794]$ & -1.230 & 0.164 & {$[-2.961$} & $0.501]$ \\
\hline Town or county & 0.507 & 0.233 & {$[-0.326$} & 1.340] & 0.495 & 0.173 & {$[-0.218$} & 1.207] \\
\hline Rural village & 0.195 & 0.596 & {$[-0.527$} & $0.918]$ & 0.167 & 0.564 & {$[-0.400$} & $0.734]$ \\
\hline \multicolumn{9}{|l|}{ Has never been left behind (reference) } \\
\hline \multicolumn{9}{|l|}{ Has been left behind: } \\
\hline $\begin{array}{l}\text { with grandparents during elementary } \\
\text { school }\end{array}$ & & & & & -0.107 & 0.456 & {$[-0.389$} & $0.175]$ \\
\hline with others during elementary school & & & & & -0.906 & 0.009 & {$[-1.584$} & $-0.227]$ \\
\hline Constant cut $_{1}$ & -2.804 & & {$[-6.114$} & $0.507]$ & -3.390 & & {$[-6.552$} & $-0.227]$ \\
\hline Constant cut ${ }_{2}$ & -1.573 & & {$[-4.404$} & $1.257]$ & -2.122 & & {$[-4.865$} & $0.621]$ \\
\hline Constant cut ${ }_{3}$ & 0.631 & & {$[-2.090$} & 3.352] & 0.154 & & {$[-2.495$} & 2.802] \\
\hline Constant cut ${ }_{4}$ & 2.464 & & {$[-0.234$} & $5.163]$ & 2.018 & & {$[-0.618$} & 4.655] \\
\hline $\mathrm{R}^{2}$ & 0.036 & & & & 0.050 & & & \\
\hline $\mathrm{N}$ & 2,279 & & & & 2,279 & & & \\
\hline
\end{tabular}


Table 4: OLS regression for mental health (GHQ score)

\begin{tabular}{|c|c|c|c|c|c|c|c|c|}
\hline \multirow{3}{*}{$\begin{array}{l}\text { Variable } \\
\text { Age }\end{array}$} & \multicolumn{4}{|l|}{ Model 5} & \multicolumn{4}{|l|}{ Model 6} \\
\hline & \multirow{2}{*}{$\begin{array}{l}\text { Coef. } \\
-0.100\end{array}$} & \multirow{2}{*}{$\begin{array}{r}\text { P value } \\
0.042\end{array}$} & \multicolumn{2}{|c|}{ 95\% Conf. Interval } & \multirow{2}{*}{$\begin{array}{l}\text { Coef. } \\
-0.082\end{array}$} & \multirow{2}{*}{$\begin{array}{r}\mathbf{P} \text { value } \\
0.083\end{array}$} & \multicolumn{2}{|c|}{ 95\% Conf. Interval } \\
\hline & & & {$[-0.195$} & $-0.004]$ & & & {$[-0.175$} & $0.011]$ \\
\hline Female & 0.248 & 0.247 & {$[-0.172$} & $0.667]$ & 0.302 & 0.134 & {$[-0.093$} & $0.696]$ \\
\hline Education years & 0.070 & 0.243 & {$[-0.047$} & $0.187]$ & 0.066 & 0.229 & {$[-0.041$} & $0.173]$ \\
\hline Migration duration (in years) & 0.003 & 0.920 & {$[-0.059$} & $0.066]$ & -0.009 & 0.773 & {$[-0.071$} & $0.053]$ \\
\hline Number of friends & -0.002 & 0.909 & {$[-0.034$} & $0.030]$ & -0.002 & 0.912 & {$[-0.036$} & $0.032]$ \\
\hline \multicolumn{9}{|l|}{ Spouse is in the same city (reference) } \\
\hline No spouse (single or divorced) & -0.016 & 0.964 & {$[-0.706$} & $0.675]$ & -0.030 & 0.926 & {$[-0.670$} & $0.610]$ \\
\hline Spouse is in another city & 0.549 & 0.384 & {$[-0.687$} & $1.785]$ & 0.606 & 0.251 & {$[-0.428$} & 1.639] \\
\hline \multicolumn{9}{|l|}{ East (reference) } \\
\hline Central & -0.044 & 0.837 & {$[-0.469$} & $0.380]$ & -0.034 & 0.870 & {$[-0.441$} & $0.373]$ \\
\hline West & 0.463 & 0.204 & {$[-0.251$} & $1.176]$ & 0.493 & 0.168 & {$[-0.207$} & 1.193] \\
\hline \multicolumn{9}{|l|}{ Central city (reference) } \\
\hline Suburb & 0.216 & 0.654 & {$[-0.728$} & $1.160]$ & 0.192 & 0.636 & {$[-0.603$} & $0.988]$ \\
\hline Town or county & 0.118 & 0.743 & {$[-0.586$} & $0.822]$ & 0.164 & 0.565 & {$[-0.395$} & $0.723]$ \\
\hline Rural village & 0.097 & 0.778 & {$[-0.580$} & $0.775]$ & 0.208 & 0.474 & {$[-0.361$} & $0.777]$ \\
\hline \multicolumn{9}{|l|}{ Has never been left behind (reference) } \\
\hline \multicolumn{9}{|l|}{ Has been left behind: } \\
\hline $\begin{array}{l}\text { with grandparents during elementary } \\
\text { school }\end{array}$ & & & & & 0.033 & 0.821 & {$[-0.251$} & $0.317]$ \\
\hline with others during elementary school & & & & & 1.143 & 0.016 & {$[0.215$,} & 2.072] \\
\hline Constant & 3.115 & 0.005 & {$[0.962$} & $5.269]$ & 2.453 & 0.056 & {$[-0.064$} & 4.970] \\
\hline $\mathrm{R}^{2}$ & 0.043 & & & & 0.085 & & & \\
\hline $\mathrm{N}$ & 2,233 & & & & 2,233 & & & \\
\hline
\end{tabular}

\section{Summary and discussion}

Recent studies have rightly focused on the educational and health consequences of parental migration for children, given the extremely large number of children affected by the migration process. Although examining the relationship between parental migration and children's well-being in a cross-sectional research design is important, it is possible that children are resilient and can overcome and recover from these early disadvantages. Some studies use longitudinal data to study children's educational and behavioral outcomes but the fundamental focus is still on outcomes during childhood. A recent and growing literature in sociology and economics journals points to earlier 
disadvantages having robust long-term consequences for adult health outcomes, prompting the current study. In the context of China's massive migration and the large number of children involved in this process, and given that migration has been going on in China for the last four decades, the time is right to depart from current approaches, and to adopt a life course approach to study the long-term consequences of migration for children.

In this section we highlight several important findings and discuss policy implications. Taking advantage of a major survey of migrant workers in the PRD and YRD, our study looks at children's left-behind status in three major stages: preelementary school, during elementary school, and during middle school. The most striking result is that negative outcomes are most often found in the elementary school years. Left-behind experience during elementary school years leads to major negative outcomes during adulthood: poor educational attainment, poor self-rated health, and poor mental health. The fact that the negative impact of being left behind during elementary school 13 years previously is manifested in three major aspects of education and health in 2010 should be of major concern to scholars and policymakers. Elementary school is a very vulnerable stage when children need supervision for school-work and to feel emotionally supported by their parents; whereas in middle school years children are more mature and better able to handle the stress caused by parental absence.

In recent years more attention has been paid to studying the role of grandparents in children's development. In traditional Chinese society, both rural and urban, grandparents often take care of children for at least some of their childhood. We observe that children whose grandparents took care of them do not show long-term negative consequence in terms of physical and mental health. This suggests that grandparents are a good substitute for parents in terms of meeting children's basic needs for food and shelter and providing emotional support. However, children raised by grandparents during their elementary years suffer educationally in the long term. Newly collected data from Shaanxi province in western China in 2017 (Yue, Liang, and Wang 2020) shows a 4-year difference in years of schooling between children brought up by grandparents and those raised by parents. Furthermore, $70 \%$ of mothers and $78 \%$ of fathers graduated from middle school, compared to only $19 \%$ of grandmothers and $46 \%$ of grandfathers. Given such a sharp educational gap between children's parents and grandparents, the negative educational consequences for the respondents who were taken care of by grandparents is unsurprising. Grandparents can be dedicated caregivers, but are not necessarily good educators. ${ }^{3}$

\footnotetext{
${ }^{3}$ We note a recent study by Zeng and Xie (2014), who have shown that grandparents have a positive impact on the education of grandchildren. However, their measure of education is children's school drop out rate,
} 
Third, the fact that some children were in boarding school during middle school years is quite encouraging. Boarding schools in rural China do not resemble boarding schools in the United States, which are often elite schools with classical-style buildings, qualified teachers, and a big budget. Boarding schools in rural China are often located in the major town in a county. The buildings are often very basic, with bunk beds and a student cafeteria. The students stay there during the week and return home during the weekend. During the week the students can concentrate on schoolwork, and one or two teachers always monitor boarding students to make sure homework is done and lights are turned off on time at night. In recent years some high-quality middle schools have provided additional academic programs for boarding students after the school term is over. This more institutionalized learning environment can improve children's educational outcomes. Although some studies suggest the contrary, we do not find boarding schools to have a long-term negative impact on students' mental health.

Our major findings have two major policy implications. First, we find long-term negative impacts in three domains (education, physical health, and mental health) from being left behind by parents during elementary school years. China has implemented some grass-root-level policies to alleviate problems for children whose parents have migrated. Leaders at the county and town level regularly visit schools with large numbers of left-behind children. We visited these rural schools in 2017 and found that many of them had organized special files/records for left-behind children to monitor their educational performance. Teachers are told not to stigmatize these left-behind children. Our paper provides empirical evidence that any school-based program to help left behind children is best served to target children in elementary schools, as opposed to pre-school children or children in middle school. Our paper suggests rural elementary schools should pay more attention to left-behind children who are cared for by grandparents, because they are more likely to need help with schoolwork.

Second, in light of the fact that the adults who went to boarding school during middle school years exhibit favorable educational outcomes, left-behind children should be encouraged to take this option. An increased demand for boarding at the middle school level would need more financial resources and would take more fiscal planning and input from the higher levels of the educational administration. However, such investment would benefit children in the long run.

As we conclude the paper, some caveats are in order. It should be noted that the survey data we use contains only migrants in the PRD and YRD. It is well known that migrants are often positively selected from migrant origins, and there are other nonmigrants who may have been left behind that we did not observe. As adult non-migrants who were left behind growing up may also have poor educational and health outcomes

which is no longer very common in rural China. In addition, they measure the short-term impact, whereas we take a long-term perspective. 
we may under-estimate the long-term negative impact of parental migration on children. We are mindful of the limitations of possible sample selection bias and omitted variables. However, a life course perspective along with cumulative empirical evidence on the long-term consequences of early life course events (as reviewed in this paper) suggest that the results in this paper are likely to be causal in nature, which can be further tested or confirmed with high quality longitudinal data. Despite the fact that our results cannot be confirmed as causal at present, the possible long-term damage to children may serve as a wake-up call for policymakers to speed up reforms that facilitate children from migrant households joining their parents in urban China. In the last two decades there has been a major data collection effort at the national level, including the China Family Panel Study, the China Labor Force Dynamics Survey, and the China Household Finance Survey. Collecting information on the early left-behind experience of today's adults would put us on firmer ground to evaluate the long-term consequences of parental migration on education and health.

\section{Acknowledgments}

The project is supported by the US National Science Foundation (SES\#1524282) and the National Social Science Foundation of China (15AZD053), whose support is gratefully acknowledged. We thank Prof. Liu Linping for giving us access to the data used for this paper. We are also grateful for comments and suggestions from several reviewers and editors. 


\section{References}

Blau, P.M. and Duncan, O.D. (1967). The American occupational structure. New York: Wiley.

Case, A., Fertig, A., and Paxson, C. (2005). The lasting impact of childhood health and circumstance. Journal of Health Economics 24(2): 365-389. doi:10.1016/j. jhealeco.2004.09.008.

Case, A. and Katz, L.F. (1991). The company you keep: The effects of family and neighborhood on disadvantaged youths. Cambridge: National Bureau of Economic Research (working paper series w3705). doi:10.3386/w3705.

Conley, D. and Bennett, N.G. (2000). Is biology destiny? Birth weight and life chances. American Sociological Review 65(3): 458-467. doi:10.2307/2657467.

De Brauw, A. and Mu, R. (2011). Migration and the overweight and underweight status of children in rural China. Food Policy 36(1): 88-100. doi:10.1016/j. foodpol.2010.08.001.

DiPrete, T. and Eirich, G.M. (2006). Cumulative advantage as a mechanism for inequality: A review of theoretical and empirical developments. Annual Review of Sociology 32: 271-297. doi:10.1146/annurev.soc.32.061604. 123127.

Edwards, A.C. and Ureta, M. (2003). International migration, remittances, and schooling: Evidence from El Salvador. Journal of Development Economics 72(2): 429-461. doi:10.1016/S0304-3878(03)00115-9.

Elder, G. (1974). Children of the great depression. Chicago: University of Chicago Press.

Elder, G. (1998). The life course as developmental theory. Child Development 69(1): 112. doi:10.1111/j.1467-8624.1998.tb06128.x.

Elman, C. and O'Rand, A. (2004). The race is to the swift: Socioeconomic origins, adult education, and wage attainment. American Journal of Sociology 110(1): 123-160. doi:10.1086/386273.

Ermisch, J.F. and Francesconi, M. (2001). Family structure and children's achievements. Journal of Population Economics 14(2): 249-270. doi:10.1007/ s001480000028.

Falbo, T. (1991). The impact of grandparents on children's outcomes in China. Marriage and Family Review 16(3-4): 369-376. doi:10.1300/J002v16n03_09.

Ferraro, K.F. and Kelley-Moore, J.A. (2003). Cumulative disadvantage and health: Long-term consequences of obesity? American Sociological Review 68(5): 707-729. doi:10.2307/1519759. 
Ferraro, K.F., Schafer, M.F., and Wilkinson, L.R. (2016). Childhood disadvantage and health problems in middle and later life: Early imprints on physical health? American Sociological Review 81: 107-133. doi:10.1177/0003122415619617.

Goldberg, D.P. (1978). Manual of the General Health Questionnaire. Windsor: NFER Nelson.

Goldberg, D.P. and Williams, P.A. (1988). User's guide to the GHQ. Windsor: NFER Nelson.

Hayward, M.D. and Gorman, B.K. (2004). The long arm of childhood: The influence of early-life social conditions on men's mortality. Demography 41(1): 87-107. doi:10.1353/dem.2004.0005.

Heckman, J.J. (2006). Skill formation and the economics of investing in disadvantaged children. Science 312(5782): 1900-1902. doi:10.1126/science.1128898.

Hildebrandt, N. and McKenzie, D.J. (2005). The effects of migration on child health in Mexico. Economia 6(1): 257-289. doi:10.1596/1813-9450-3573.

Hogan, D.P. (1981). Transitions and social change: The early lives of American men. New York: Academic Press.

Kuh, D. and Ben-Shlomo, Y. (eds.). (1997). A life course approach to adult disease. Oxford: Oxford University Press.

Liang, Z. (2016). China's great migration and the prospects of a more integrated society. Annual Review of Sociology 42(1): 451-471. doi:10.1146/annurevsoc-081715-074435.

Liang, Z., Li, J., and Ma, Z. (2013). Migration and remittances: Evidence from a poor province in China. Asian Population Studies 9(2): 124-141. doi:10.1080/174 41730.2013.785721.

Liang, Z., Li, J., and Ma, Z. (2014). Changing patterns of the floating population in China, 2000-2010. Population and Development Review 40(4): 695-716. doi:10.1111/j.1728-4457.2014.00007.x.

Liu, H. (2010). An investigation on perceived academic self-efficacy and its causes for the left-behind children of rural boarding schools [Master's thesis]. Hangzhou: Zhejiang University, Faculty of Science, Applied Psychology Program.

Liu, L., Yong, X., and Shu, F. (2011). Regional differences in labor rights: A survey of rural migrant workers in the Pearl River Delta and the Yangtze River Delta. Social Sciences in China 2: 107-123+222. [in Chinese]

Liu, L., Zheng, G., and Sun, Z. (2011). Labor rights and mental Health: Survey on migrant workers in Pearl River Delta and Yangtze River Delta. Sociological Research 4:164-184. [in Chinese]

Lu, Y. (2012). Education of children left behind in rural China. Journal of Marriage and Family 74(2): 328-341. doi:10.1111/j.1741-3737.2011.00951.x. 
Ma, X., Ling, H., Li, X., and Wang, M. (2013). Learning adaptability, mental health of pupils in boarding and nonboarding schools. Chinese Journal of Clinical Psychology 21(3): 497-499. [in Chinese]

Mayer, K. (2009). New directions in life course research. Annual Review of Sociology 35: 413-433. doi:10.1146/annurev.soc.34.040507.134619.

McCaffrey, D.F., Griffin, B.A., Almirall, D., Slaughter, M.E., Ramchand, R., and Burgette, L.F. (2013). A tutorial on propensity score estimation for multiple treatments using generalized boosted models. Statistics in Medicine 32(19): 3388-3414. doi:10.1002/sim.5753.

Merton, R.K. (1968). The Matthew effect in science: The reward and communication systems of science are considered. Science 159(3810): 56-63. doi:10.1126/ science.159.3810.56.

Piccinelli, M., Bisoffi, G., Bon, M., Cunico, L., and Tansella, M. (1993). Validity and test-retest reliability of the Italian version of the 12-item General Health Questionnaire in general practice: A comparison between three scoring methods. Comprehensive Psychiatry 34(3): 198-205. doi:10.1016/0010-440 X(93)90048-9.

Raley, K.R. and Wildsmith, E. (2004). Cohabitation and children's family instability. Journal of Marriage and Family 66(1): 210-219. doi:10.1111/j.0022-2445. 2004.00014.x-i1.

Ren, Q. and Treiman, D.J. (2015). Living arrangements of the elderly in China and consequences for their emotional well-being. Chinese Sociological Review 47(3): 255-286. doi:10.1080/21620555.2015.1032162.

Robles, V. and Oropesa. R.S. (2011). International migration and the education of children: Evidence from Lima, Peru. Population Research and Policy Review 30(4): 591-618. doi:10.1007/s11113-011-9202-9.

Shi, Y., Bai, Y., Shen, Y., Kenny, K., and Rozelle, S. (2016). Effects of parental migration on mental health of left-behind children: Evidence from northwestern China. China and World Economy 24(3): 105-122. doi:10.1111/ cwe.12161.

Stark, O. and Bloom, D.E. (1985). The new economics of labor migration. The American Economic Review 75(2): 173-178.

Von Korff, M. and Üstün, T.B. (1995). Methods of the WHO collaborative study on psychological problems in general health care. In: Sartorius N., Üstün, T.B., and World Health Organization (eds.). Mental illness in general health care: An international study. Chichester: Wiley: 19-38.

Wen, M. and Lin, D. (2012). Child development in rural China: Children left behind by their migrant parents and children of nonmigrant families. Child Development 83(1): 120-136. doi:10.1111/j.1467-8624.2011.01698.x. 
$\mathrm{Xu}, \mathrm{H}$. and Xie, Y. (2015). The causal effects of rural-to-urban migration on children's well-being in China. European Sociological Review 31(4): 502-519. doi:10.10 93/esr/jcv009.

Ye, J. and Murray, J. (2005). Left-behind children in rural China. Beijing: Social Sciences Academic Press.

Yue, Z., Liang, Z., and Wang, Q. (2020). The impact of parental migration on depression of children: New evidence from rural China. Chinese Sociological Review. Forthcoming.

Zeng, Z. and Xie, Y. (2014). The effects of grandparents on children's schooling evidence from rural China. Demography 51(2): 599-617. doi:10.1007/s13524013-0275-4.

Zhang, H., Behrman, J.R., Fan, C.S., Wei, X., and Zhang, J. (2014). Does parental absence reduce cognitive achievements? Evidence from rural China. Journal of Development Economics 111: 181-195. doi:10.1016/j.jdeveco.2014.09.004.

Zhang, Y., Cui, L., Li, K., Jiang, Q., Sun, X., Gao, L., Han, Y., Li, Y., Liu, Y., Yan, B., Lv, H., and Yang, B. (2008). Supplemented edition of the General Health Questionnaire (GHQ12) in epidemiological survey of mental illness. Chinese Mental Health Journal 22(3): 189-192. [in Chinese]

Zhao, M., Derudder, B., and Huang, J. (2017). Polycentric development in China's mega-city regions, 2001-08: A comparison of the Yangtze and Pearl River Deltas. Journal of the Geographical Society of Berlin 148(1): 1-13.

Zhou, M., Murphy, R., and Tao, R. (2014). Effects of parents' migration on the education of children left behind in rural China. Population and Development Review 40(2): 273-292. doi:10.1111/j.1728-4457.2014.00673.x.

Zhou, X. and Hou, L. (1999). Children of the Cultural Revolution: The state and the life course in the People's Republic of China. American Sociological Review 64(1): 12-36. doi:10.2307/2657275.

Zulkefly, N.S. and Baharudin, R. (2010). Using the 12-item General Health Questionnaire (GHQ-12) to assess the psychological health of Malaysian college students. Global Journal of Health Science 2(1): 73-80. doi:10.5539/ gjhs.v2n1p73. 
Liang \& Sun: The lasting impact of parental migration on children's education and health outcomes in China

\section{Appendix}

\section{Table A-1: General Health Questionnaire (12-item)}

Please fill this form according to your experience in the past two weeks:

\begin{tabular}{l} 
Health condition \\
1. Lost a lot of sleep due to anxiety \\
\hline 2. Under strain \\
\hline 3. Able to concentrate \\
\hline 4. Played a useful part in things \\
\hline 5. Faced up to problems \\
\hline 6. Capable of making decisions \\
\hline 7. Could not overcome difficulties \\
\hline 8. Felt happy \\
\hline 9. Enjoyed normal activities \\
\hline 10. Felt unhappy and depressed \\
\hline 11. Lacking confidence \\
\hline 12. Thinking of self as worthless \\
\hline
\end{tabular}

Table A-2: Multinomial logistic regression for treatment (left-behind status during elementary school) in Model 1, Table 2

\begin{tabular}{|c|c|c|c|c|c|c|c|c|}
\hline \multirow[b]{4}{*}{ Age } & \multicolumn{8}{|c|}{ Model A1 } \\
\hline & \multicolumn{4}{|c|}{ With grandparents } & \multicolumn{4}{|c|}{ With others } \\
\hline & \multirow{2}{*}{$\begin{array}{l}\text { Coef. } \\
-0.150\end{array}$} & \multirow{2}{*}{$\begin{array}{r}\text { P value } \\
0.000\end{array}$} & \multicolumn{2}{|c|}{$95 \%$ Conf. interval } & \multirow{2}{*}{$\begin{array}{l}\text { Coef. } \\
-0.064\end{array}$} & \multirow{2}{*}{$\begin{array}{r}\text { P value } \\
0.181\end{array}$} & \multicolumn{2}{|c|}{$95 \%$ Conf. Interval } \\
\hline & & & {$[-0.192$} & $-0.108]$ & & & {$[-0.158$} & $0.030]$ \\
\hline Female & 0.137 & 0.334 & {$[-0.141$} & $0.414]$ & -0.119 & 0.720 & {$[-0.767$} & 0.530] \\
\hline \multicolumn{9}{|l|}{ East (reference) } \\
\hline Central & 0.179 & 0.304 & {$[-0.162$} & $0.521]$ & -0.117 & 0.762 & {$[-0.875$} & $0.641]$ \\
\hline West & 0.214 & 0.252 & {$[-0.153$} & $0.581]$ & -0.335 & 0.461 & {$[-1.223$} & $0.554]$ \\
\hline $\begin{array}{l}\text { Percentage of non-agricultural } \\
\text { population }\end{array}$ & -0.262 & 0.675 & {$[-1.489$} & $0.965]$ & -0.982 & 0.462 & {$[-3.597$} & 1.633] \\
\hline GDP per capita (in thousands) & -0.021 & 0.452 & {$[-0.075$} & $0.033]$ & 0.013 & 0.718 & {$[-0.058$} & $0.084]$ \\
\hline Employment rate & 0.068 & 0.586 & {$[-0.177$} & $0.313]$ & -0.441 & 0.039 & {$[-0.860$} & $-0.022]$ \\
\hline Constant & -5.469 & 0.660 & {$[-29.871$} & 18.932] & 41.581 & 0.052 & {$[-0.344$} & $83.506]$ \\
\hline Pseudo $\mathrm{R}^{2}$ & 0.037 & & & & & & & \\
\hline $\mathrm{N}$ & 2,307 & & & & & & & \\
\hline
\end{tabular}

${ }^{\text {a }}$ Category "not left behind" as reference 
Table A-3: Multinomial logistic regression for treatment (left-behind status during middle school) in Model 2, Table 2

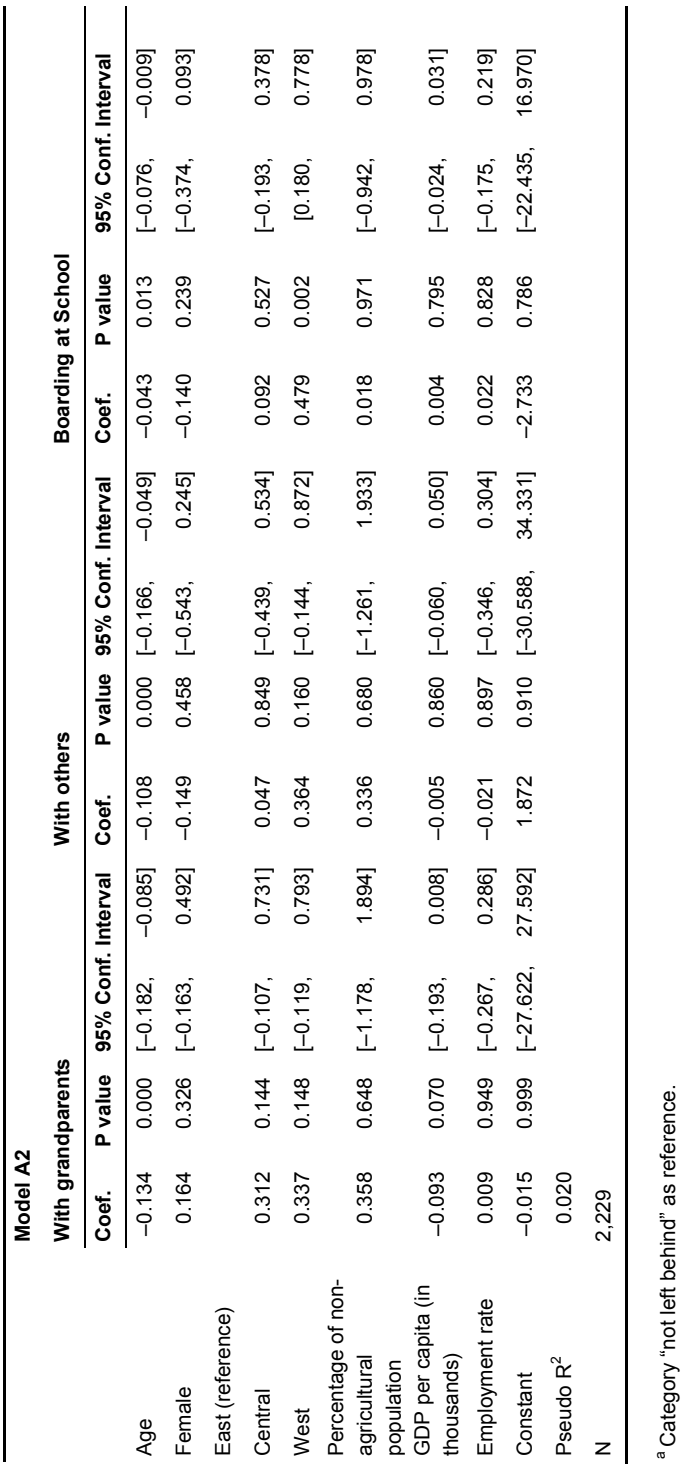


Table A-4: Multinomial logistic regression for treatment (left-behind status during elementary school) in Model 3 and 4, Table 3

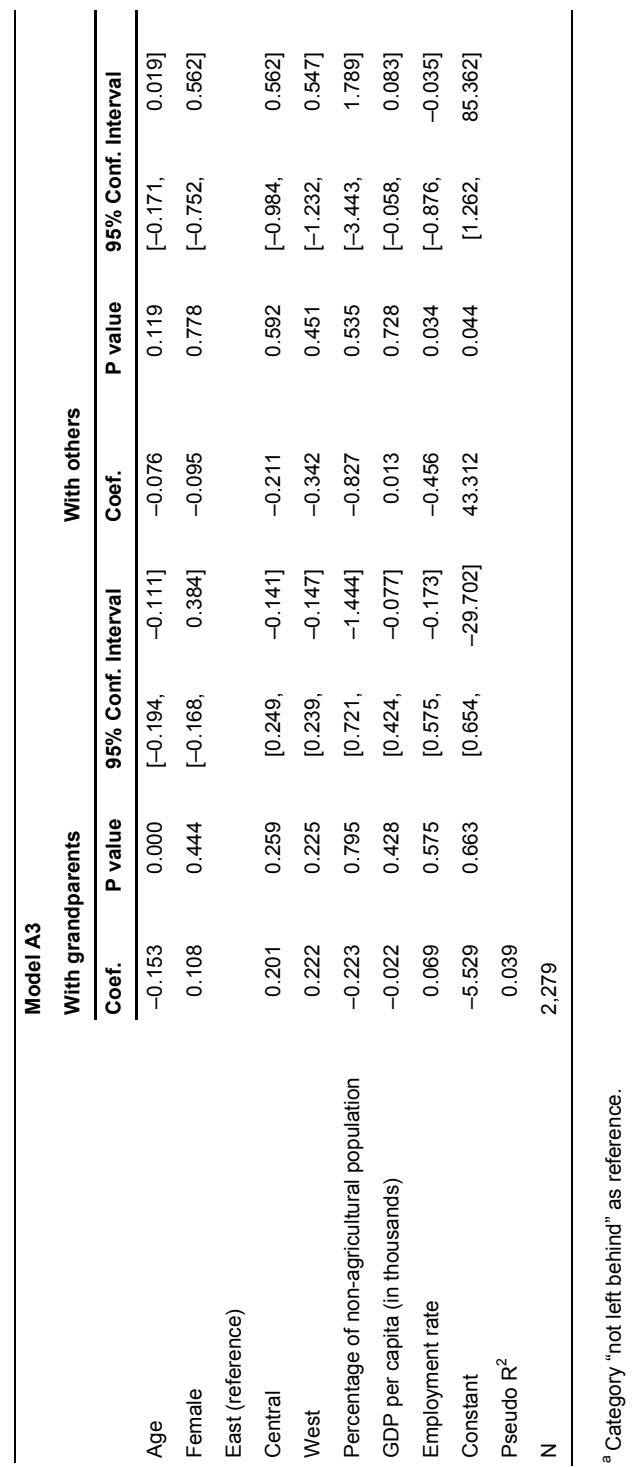


Table A-5: Multinomial logistic regression for treatment (left-behind status during elementary school) in Model 5 and 6, Table 4

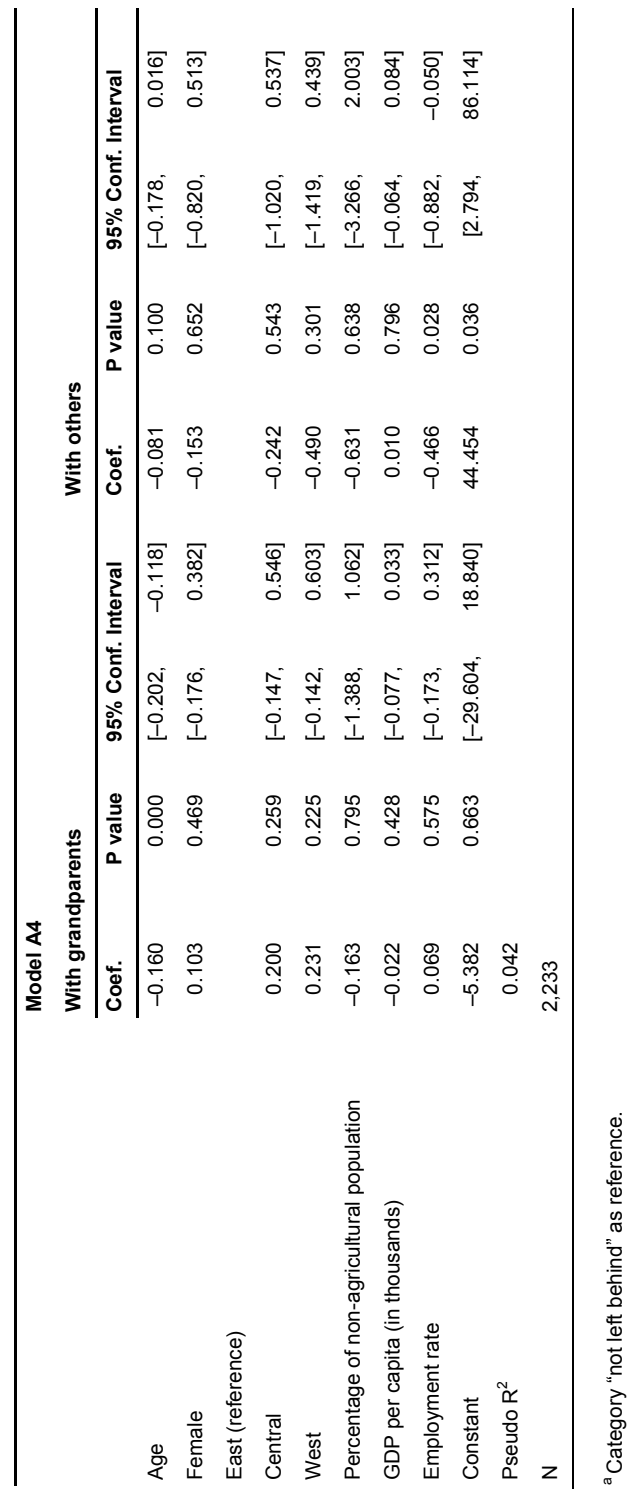


Liang \& Sun: The lasting impact of parental migration on children's education and health outcomes in China 